\title{
Isolation, identification of Phytophthora nicotianae var. parasitica and screening of tomato parental lines for buckeye rot resistance
}

\author{
Shilpa $^{1^{*}}$, Rajinder Kaur ${ }^{1}$, Monica Sharma ${ }^{2}$ and M. N. Adarsh ${ }^{3}$ \\ ${ }^{1}$ Department of Biotechnology, Dr Y S Parmar University of Horticulture and Forestry, Nauni, Solan-173230 \\ (Himachal Pradesh), INDIA \\ ${ }^{2}$ Department of Plant Pathology, Dr Y S Parmar University of Horticulture and Forestry, Nauni, Solan-1732309 \\ (Himachal Pradesh), INDIA \\ ${ }^{3}$ Department of Vegetable Science, Dr Y S Parmar University of Horticulture and Forestry, Nauni, Solan-173230 \\ (Himachal Pradesh), INDIA \\ *Corresponding author. E-mail: shilpachaudhary05@gmail.com \\ Received: June 23, 2016; Revised received: January 26, 2017; Accepted: February 21, 2017
}

\begin{abstract}
Buckeye rot disease of tomato which is one of the most devastating diseases of tomato crop is caused by soil born fungus Phytophthora nicotianae var. parasitica. In present study, the pathogen was isolated, morphologically identified and its pathogenicity was proved on susceptible commercial variety Solan Lalima and resistant line EC-251649 of tomato. Isolation of pathogen from the infected tomato fruit was achieved on Corn Meal Agar (CMA) out of two different media viz., Potato Dextrose Agar (PDA) and CMA. Fungal inoculum was prepared on Corn Meal broth. Inoculation with $10 \mathrm{ml}$ of inoculum was found optimum in plant parts namely, stem, leaves and fruits. Parental lines were inoculated to test their disease reaction to buckeye rot. Symptoms of infection appeared on leaves and fruits only. Solan Lalima was found to be highly susceptible to with disease severity of $92 \%$ and $100 \%$ disease incidence, while EC-251649 was found moderately resistant on the basis of $16 \%$ disease severity and $10 \%$ disease incidence to the disease. After confirmation of resistance and susceptibility, the parental lines were surveyed for polymorphism using 42 primers and 32 were recorded to be polymorphic revealing that the differences are present at DNA level also. This is the very first study which evaluated parental lines for buckeye rot disease reaction on morphological as well as molecular basis. These lines will be further used for quantitative trait loci (QTL) analysis/gene tagging for buckeye rot and marker assisted selection to provide improved varieties to the farmers.
\end{abstract}

Keywords: Medium, Molecular markers, Polymorphism, Tomato

\section{INTRODUCTION}

Tomato (Solanum lycopersicum L.), is one of the most economically important and widely grown vegetable crop in family Solanaceae. It is the second most consumed vegetable crop after potato with production of 163.4 million tonnes. China accounted for $31 \%$ of the total, followed by India, the United States and Turkey (FAOSTAT, 2015). One of the problems of tomato cultivation is the damage caused by pathogens, including virus like Tomato mosaic virus (ToMV), Tomato spotted wilt virus, Potato virus Y, bacteria like Xanthomonas campestris, Clavibacter michiganensis, Pseudomonas syringae, nematode and fungi such as Alternaria solani, Alternaria tenuis, Phytophthora infestans, Phytophthora nicotianae var. parasitica, Colletotrichum phomoides, and Fusarium sp. One of the most devastating diseases is buckeye rot which causes 30-40 per cent crop loss which may rise with the prevalence and severity of disease depending upon the favourable weather conditions (Gupta et al., 2005). Sherbakoff in 1917 reported buckeye rot for the very first time from Florida (Wani, 2011). In India, this disease has been reported for the first time from Solan area of Himachal Pradesh (Jain et al., 1961). Buckeye rot of tomato fruit is caused by soil borne fungus Phytophthora nicotianae var. parasitica. Initial symptoms consist of a brownish, water-soaked circular spot that usually appears near the blossom end, or at the point of contact between the fruit and soil (Tiwari et al., 2014). The disease most commonly occurs under prolonged warm and wet conditions. The buckeye rot fungus may be introduced through infected seeds or transplants, by contact with infested soil or through plants from the previous crop. Temperatures between $23{ }^{\circ} \mathrm{C}$ and $30{ }^{\circ} \mathrm{C}$ are ideal for disease development. Spores can germinate in soil or on decaying debris. Splashing rain and surface water can disperse spores onto healthy plants. Susceptible tomato plants can be killed within three weeks of transplantation into infected soil. The fungus is also seed-borne and may be spread by contaminated seed leading to failure of germination. (AVRDC, 2004; Lu et al., 2013). As till date no variety with resistance to this disease is available, 
thus the only management options are cultural and chemical control (Bijaya et al., 2002; Olanya and Larkin, 2006). But in case of severe infection by the pathogen these control measures do not prove more effective. Thus, another way to combat this disease is by the development of resistant varieties by identifying a susceptible commercial variety and resistance source. The wild cherry tomatoes are supposed to contain resistant genes for this disease. The susceptible and resistant parents can then be used for breeding purpose. The present study was designed to fulfill following objectives: Isolation of Phytophthora nicotianae var. parasitica, morphological identification of the fungus, morphological and molecular screening of susceptible and resistant varieties.

\section{MATERIALS AND METHODS}

Isolation and morphological identification of pathogen: For isolation of pathogen, buckeye rot infected fruit of tomato, obtained from fields of Department of Plant Pathology, Dr YS Parmar University of Horticulture and Forestry, Nauni, Solan (HP) showing brownish pattern of concentric rings, was used (Fig. 1). After this the fruit was washed with autoclaved distilled water. Then part of fruit around infected portion was used for culturing on two different media viz., corn meal agar (CMA) and Potato Dextrose Agar (PDA). For proper growth of fungal isolate, the culture room temperature was maintained at $25{ }^{0} \mathrm{C}$ (Fig. 2). After this, morphological characterization of fungus (Fig. 3) was carried which included colony morphology and microscopic structures of the fungus. The mycelium was hyaline, coenocytic and produced sporangiophores. Sporangiophores were sympodially branched, had swelling at the nodes and produced lemon-shaped, papillate sporangia.

Maintenance of pure culture and preparation of fungal inoculum for screening: The culture of $P$. nicotianae var. parasitica was maintained on CMA medium in the petriplates by culturing a single bit of previously grown culture to obtain pure culture of pathogen. Then the culture was incubated at $25^{\circ} \mathrm{C}$ for 10 days till uniform fluffy growth was obtained. Thereafter, the culture plates with pathogen were covered properly and kept at low temperature $\left(4^{\circ} \mathrm{C}\right)$ to stop further growth.

After morphological confirmation, a dilute suspension of fungal cells was prepared on Corn Meal broth (CM) (Fig. 4). After ten days of mycelial growth, the density of fungal inoculum was standardized using haemocytometer for inoculating fruits. Optimum density of 1520 hyphae/ $\mathrm{ml}$ in haemocytometer was obtained by mixing $1 \mathrm{gm}$ of fungal hyphae in $80 \mathrm{ml}$ distilled water. Then the fungal inoculum was used to infect the fruits of tomato at different concentrations viz., $2 \mathrm{ml}, 5 \mathrm{ml}$, $10 \mathrm{ml}$ and $15 \mathrm{ml}$. Inoculation with $10 \mathrm{ml}$ of inoculum was found most effective. Too low concentrations i.e.

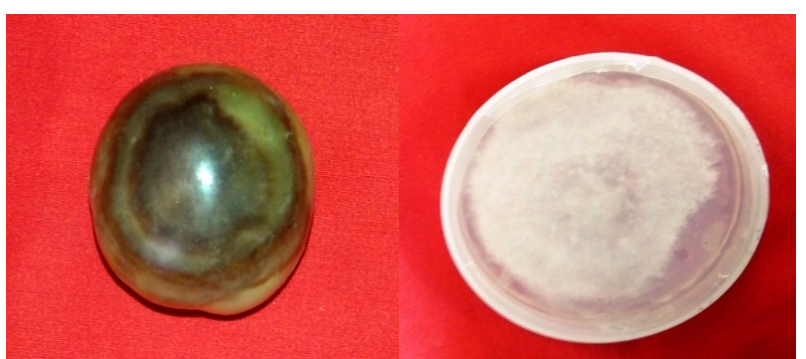

Fig. 1. Buckeye rot infected Fig. 2. P. nicotianae var. tomato fruit used for isola- parasitica on CMA medium tion of $P$. nicotianae var. after one week of culturing. parasitica

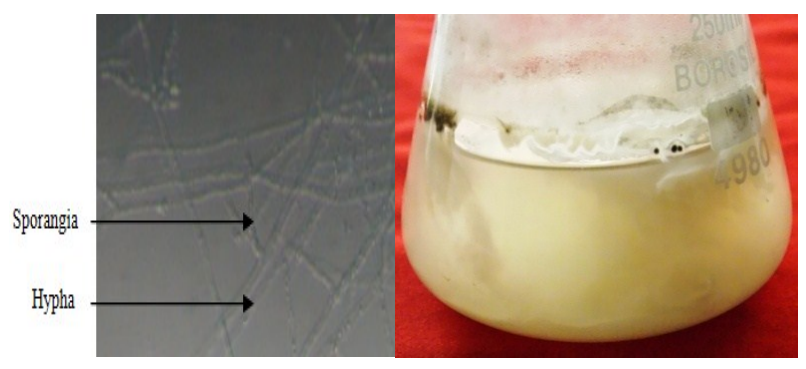

Fig. 3. Microscopic view of Fig. 4. Liquid culture of $P$. P. nicotianae var. Parasiti- nicotianae var. parasitica ca. after ten days of inoculation.

$2 \mathrm{ml}$ and $5 \mathrm{ml}$ did not cause much damage, while too high concentration i.e. $15 \mathrm{ml}$ cause early and complete damage of fruit.

Pathogenicity test of parents using fungal inoculum: Pathogenicity test was conducted on different parts of tomato plant viz, stem, leaves and fruits by injecting $10 \mathrm{ml}$ of inoculum and incubated in humid chamber for 10 days. To conduct pathogenicity test two parental lines 'Solan Lalima' (susceptible) and 'EC-251649' (resistant) to buckeye rot were used. Infected material was observed periodically for the appearance of symptoms like formation of brownish spot and pattern of concentric ring of brown bands on the fruits. In case of fruits, screening was done by using two methods: Detached fruit method and Intact fruit method. In case of leaves, disease was measured by using 0-5 scale adopted by Dodan et al. (1995) and disease severity was calculated using the formula:

Disease severity $(\%)=\frac{\sum \text { All disease rating }}{\text { Total leaves in all grades } \mathrm{X} \text { maximum disease grade }} \mathrm{X}$.00

After calculating disease severity, the scale given in Table 1 was used for assessing disease reaction on leaves, depending on which leaves were grouped in different categories.

The disease incidence was calculated in case of fruits using following formula:

$$
\text { Disease incidence }(\%)=\frac{\text { Number of diseased fruits }}{\text { Total number of fruits }} \text { X100 }
$$

After calculation of disease incidence, the scale given 
Table 1. Scale for assessing disease reaction on leaves.

\begin{tabular}{lll}
\hline Grade & Disease Severity (\%) & Reaction \\
\hline 1 & $0.1-10.0$ & Resistant \\
2 & $10.0-20.0$ & Moderately Resistant \\
3 & $20.1-30.0$ & Moderately Susceptible \\
4 & $30.1-50.0$ & Susceptible \\
5 & 50.1 and above & Highly Susceptible \\
\hline
\end{tabular}

Table 2. Scale for assessing disease reaction on fruits.

\begin{tabular}{ll}
\hline Infected Fruits (\%) & Category/ Disease reaction \\
\hline $0-5.0$ & Resistant \\
$5.1-15.0$ & Moderately Resistant \\
$15.1-30.0$ & Moderately Susceptible \\
$30.1-45.0$ & Susceptible \\
or above & Highly Susceptible \\
\hline
\end{tabular}

in Table 2 was used for assessing disease reaction on fruits, depending on it the fruits of each plant were grouped in different categories.

Molecular screening of parental lines: Molecular screening of parental lines was done to find out polymorphism at genomic level. To carry out polymorphism studies among parental lines DNA from leaves of seedlings was isolated using the Cetyl trimethyl ammonium bromide (CTAB) method (Doyle and Doyle, 1987). For isolation extraction buffer was prepared which contained $1.5 \%$ CTAB, $20 \mathrm{mM}$ EDTA (pH 8.0), 1.4 M NaCl, $100 \mathrm{mM}$ Tris $\mathrm{HCl}(\mathrm{pH} \mathrm{8.0),} 1 \%$ polyvinylpyrrolidone (PVP) and $0.2 \% \quad \beta$ mercaptoethanol. Isolated DNA was purified following treatments with RNase $(10 \mu \mathrm{g} / \mu \mathrm{l})$, chloroform-phenol, $3 \mathrm{M}$ sodium acetate and absolute ethanol followed by suspension and precipitation using absolute alcohol to obtain the pure DNA pellet. The pellet was dissolved in Tris EDTA (TE) buffer $(10 \mathrm{mM}$ tris $\mathrm{HCl}$ and $1 \mathrm{M}$ EDTA, pH 8) and stored at $4{ }^{\circ} \mathrm{C}$ until used.

PCR-Amplification of genomic DNA: Isolated DNA was subjected to PCR for amplification by using primers (Table 3). A reaction mixture of $20 \mu \mathrm{l}$ for PCR analysis was prepared using $1 \mathrm{X}$ PCR buffer, $2 \mathrm{mM}$ $\mathrm{MgCl}_{2}, 1 \mathrm{mM}$ dNTPs, 20 picomoles each primer (forward and reverse), $1 \mathrm{U}$ Taq DNA Polymerase, 50 ng template DNA following a thermal profile as: $5 \mathrm{~min}$ of initial denaturation at $95^{\circ} \mathrm{C}$ followed by 40 cycles of 1 min denaturation at $94{ }^{\circ} \mathrm{C}$, annealing varied with $\mathrm{Tm}$ of each primer for $1 \mathrm{~min}$ and extension of $2 \mathrm{~min}$ at $72{ }^{\circ} \mathrm{C}$, further followed by final extension of $5 \mathrm{~min}$ at $72{ }^{\circ} \mathrm{C}$ (Kaur et al., 2015). The amplified DNA was mixed thoroughly with $6 \mathrm{X}$ loading dye $(0.25 \%$ Bromophenol blue, $40 \%$ Sucrose) followed by electrophoresis in $3.5 \%$ agarose gel supplemented $0.5 \mu \mathrm{g} / \mathrm{ml}$ Ethidium Bromide within $1 \mathrm{X}$ TAE buffer $(40 \mathrm{mM}$ Tris-acetate, $1.0 \mathrm{mM}$ EDTA). The gel was run at constant voltage at the rate of $5 \mathrm{~V} / \mathrm{cm}$ for about 3 hours. For PCR amplification three different types of molecular markers viz., ISSR, genomic and EST-SSRs were used.

\section{RESULTS AND DISCUSSION}

Isolation and morphological identification of pathogen: Isolation of fungus was successfully achieved on CMA (Fig.2). The fungal mycelium were hyaline, coenocytic with sympodially branched sporangiophores, had swelling at the nodes and produced lemon-shaped, papillate sporangia (Fig.3).

Pathogenicity test: Dilute suspension of fungal cells in Corn Meal broth inoculum was prepared as standardized (Fig. 4) which was then inoculated @10 ml in different plant parts. After injection of $10 \mathrm{ml}$ inoculum in stem, fruits and spray on leaves, it was found that no symptoms of infection appeared on stem leading to the conclusion that this fungus has no delirious effect on stem portion (Fig. 5 a,b). Symptoms appeared as dead brown area on leaves and formation of brown concentric rings on fruits. So, data was recorded for disease severity of leaves and disease incidence on fruits of tomato. In case of fruits, inoculation was also conducted under in vivo conditions. Data on disease severity and in incidence revealed that Solan Lalima is highly susceptible to buckeye rot (Fig. 6a, 7a, 8b), while EC-251649 was found moderately resistant to this disease (Fig. 6b, 7b, 8a and Table 3).

Molecular screening of parental lines: A total of 45 primers which included 15 of each ISSR, genomic SSR and EST-SSR primers were used to conduct parental polymorphism survey. Out of these 32 primers were found polymorphic (overall $71.11 \%$ polymorphism) between parents including 13 ISSRs, 7 genomic SSRs and 12 EST-SSRs, giving a percentage of 86.66, 56.66 and 80.0, respectively (Table 4). This study confirmed presence of variations between parents at genomic level. These results produced by molecular markers confirmed that the two parents which were proved contrasting at phenotypic level for disease resistance and susceptibility are also contrasting at genomic level (Fig. 9).

In the studies conducted earlier various media were optimized which included CMA, lima bean agar (LBA), modified lima bean agar (MLBA), malt extract agar (MEA), oat meal agar (OMA) and PDA with 90.0 $\mathrm{mm}, 31.2 \mathrm{~mm}, 49.2 \mathrm{~mm}, 51.0 \mathrm{~mm}, 90.0 \mathrm{~mm}$ and 79.3 $\mathrm{mm}$ mycelium, respectively, after seven days of culturing, but CMA medium was recorded as one of the best media for Phytophthora nicotianae growth (Bowers and Locke, 2004; Flores et al., 2013). The identifying features i.e. mycelium with hyaline, coenocytic, finely

Table 3. Disease severity and disease incidence percent and score in tomato parental lines after eight days of inoculation.

\begin{tabular}{lllll}
\hline Germplasm Name & Disease Severity & Reaction & Disease Incidence (\%) & Category \\
\hline Solan Lalima & 92.00 & Highly Susceptible & 100.00 & Highly Susceptible \\
EC-251649 & 16.00 & Moderately Resistant & 10.00 & Moderately Resistant \\
\hline
\end{tabular}




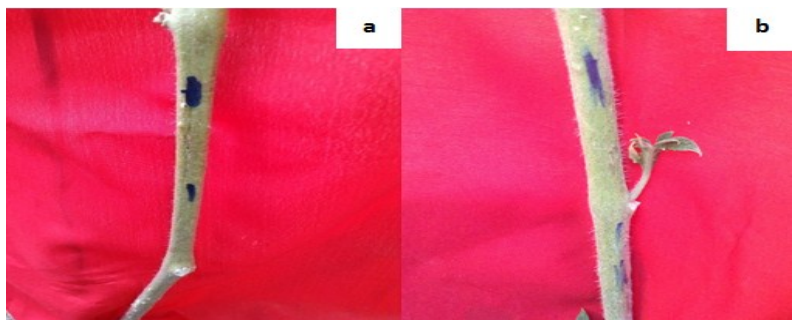

Fig. 5. Stem of highly susceptible variety (a) and moderately resistant line (b) No symptoms of infection after eight days of

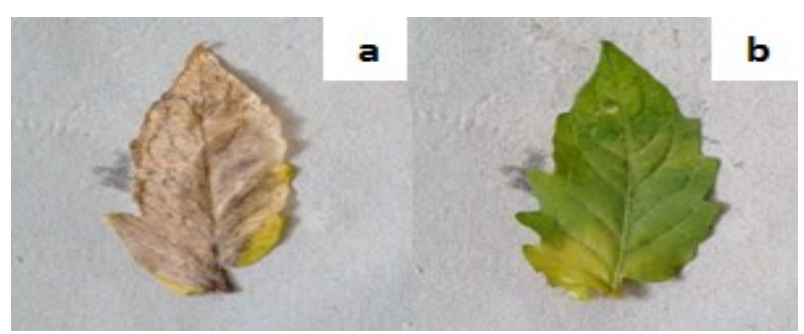

Fig. 6. Leaves of highly susceptible variety (a) and moder-
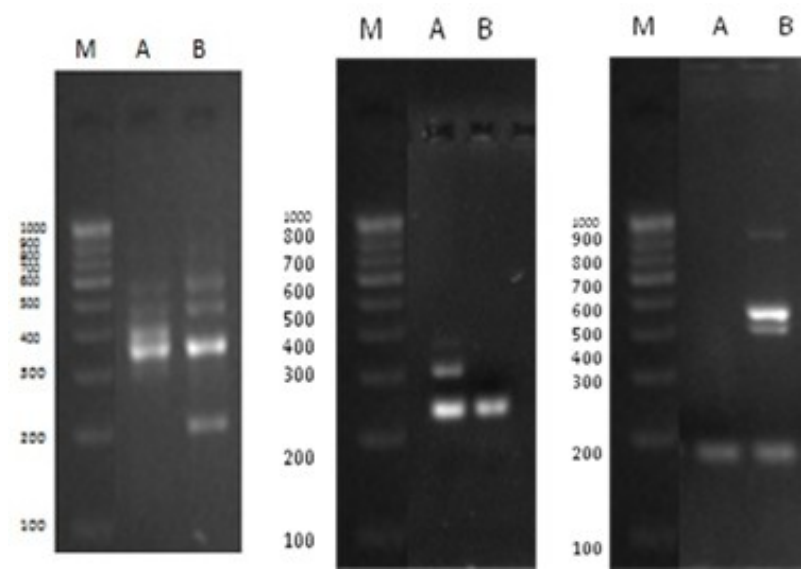

Fig. 9. Polymorphism among the parental lines using ISSR, genomic SSR and EST-SSR primers. M: Marker; A: Highly susceptible parent; $B$ : Moderately resistant parent.

granular protoplasm, branching typically at right angles with slight constriction at the point of branching matched with standard keys given by Ribeiro (1978). Screening against buckeye rot disease under laboratory conditions has been done earlier by Oliva-Risco (1983) following different methods viz. fruit dip followed by inoculation (50\%), fruit dip-injury-inoculation (100 $\%)$ and injury-fruit dip-inoculation $(66.68 \%)$. The data of disease incidence was recorded for ten days when $100 \%$ disease appeared in one of the treatments. Among these methods injury-fruit dip-inoculation was found most effective with value of $66.68 \%$ disease incidence. In present study, inoculation using a syringe was found successful for injecting inoculum in fruits and stem. But in case of leaves, spray of fungal inoculum was used successfully for establishment of infection. The screening results on fruits and leaves were

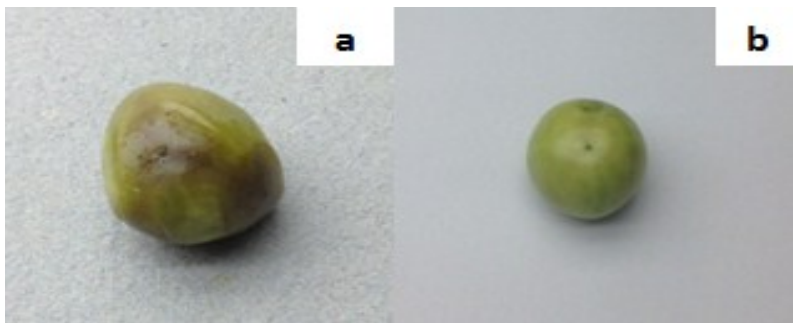

Fig. 7. Fruits of highly susceptible variety (a) and moderately resistant line (b) after eight days of in vitro inoculation.

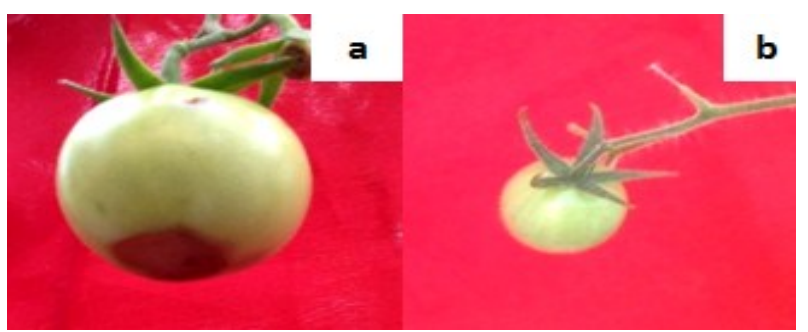

Fig. 8. Eight days in vivo inoculation results of fruits of high-

found congruent with each other which categorized the parent lines used in highly susceptible with $92.16 \%$ disease severity and $100 \%$ disease incidence and moderately resistant range with $16.00 \%$ disease severity and $10.00 \%$ disease incidence. It is noteworthy that highly susceptible parent 'Solan Lalima' is a promising variety with high yield, while moderately resistant parent 'EC-251649' is a small fruited line. Mehta (2004) also reported some level of resistance with 15 to $30 \%$ disease incidence in small fruited lines viz., EC 174041, EC 141887 and FT5-5. Difference between two parents was also revealed by three different types of molecular markers viz., ISSR, genomic SSR and EST-SSR with 86.66, 56.66 and $80.00 \%$ polymorphism, respectively. High polymorphism results indicated that the variations which are present at morphological level also exist at DNA level and are not merely due to environmental conditions. Three different types of molecular marker systems were used to produce more authenticated results. This is the very first study in which infection caused by fungus $P$. nicotianae var. parasitica were reported on leaves. Although, the main plant part more prone of infection remains the fruit, but infection also appear on leaves. There are no earlier reports on use of molecular markers for studying polymorphism at DNA level between any parental lines either susceptible or resistant to buckeye rot.

\section{Conclusion}

Isolation and conservation of Phytophthora genus is very laborious. Thus, the work on search of better options for both mycelial growth and sporulation for different isolates of Phytophthora is a continuous process. To carry out any kind of study related to 
disease whether it is screening of available varieties, inoculation work or phenotypic aspects, isolation of pure culture is the prerequisite. Till date, there is no resistant variety to buckeye rot. But from the present study it was concluded that moderate resistance (with only $16.00 \%$ disease severity and $10 \%$ disease incidence) exists in small fruited lines. While the susceptible variety fell into highly susceptible category with $92.16 \%$ disease severity and $100 \%$ disease incidence. This high level of difference was confirmed by $71.11 \%$ marker polymorphism. This report is a first of its kind which used molecular markers along with

Table 4. List of primers used to study parental polymorphism.

\begin{tabular}{|c|c|c|}
\hline Primer Name & Primer sequence $\left(5^{\prime} \rightarrow 3^{\prime}\right)$ & Annealing Temperature $\left({ }^{0} \mathrm{C}\right)$ \\
\hline \multicolumn{3}{|l|}{ ISSR primers } \\
\hline Primer1 & CACACACACACACACAAGG & 56 \\
\hline UBC-841 & GAGAGAGAGAGAGAGACTC & 57 \\
\hline UBC-808 & AGAGAGAGAGAGAGAGC & 52 \\
\hline ISSR-HB-12 & CACCACCACGC & 38 \\
\hline ISSR-HB-15 & GTGGTGGTGGC & 38 \\
\hline ISSR-HB-10 & GAGAGAGAGAGACC & 44 \\
\hline ISSR-HB-11 & GTGTGTGTGTGTCC & 44 \\
\hline UBC-840 & GAGAGAGAGAGAGAGACTC & 57 \\
\hline IISRS-3-M & ACACACACACACACAC & 50 \\
\hline IISRS-3-N & CACACACACACACACATG & 53 \\
\hline ISSR-7 & ACACACACACACACACYC & 55 \\
\hline Primer2 & TGTGTGTGTGTGTGTGC & 52 \\
\hline UBC-854 & TCTCTCTCTCTCTCTCCAGG & 60 \\
\hline \multicolumn{3}{|c|}{ EST-SSR primers } \\
\hline \multirow[t]{2}{*}{ Contig 143} & F:GTCATCGACGAAACAAAGCA & 45.00 \\
\hline & R:CTTGCCTCTTGATCTTCGCC & 55.00 \\
\hline \multirow[t]{2}{*}{ Contig 162} & F:TAATGCTGGACCTGGAACCA & 50.00 \\
\hline & R:GTCAGCAATAACCACAGGCT & 50.00 \\
\hline \multirow[t]{2}{*}{ Contig 265} & F:GGTGGAGGTGGGCATAATGA & 55.00 \\
\hline & R:GTAATTGATCCACCGGCGTC & 55.00 \\
\hline \multirow[t]{2}{*}{ Contig 340} & F:GCCCTCTTGAGGACTTGGAG & 60.00 \\
\hline & R:ACCTTCAAAAGCAGTGCAGC & 50.00 \\
\hline \multirow[t]{2}{*}{ Contig 352} & F:GAACGCTCCCTCTACCTTTT & 50.00 \\
\hline & R:TAACTTTCAGCTGGCTCACC & 50.00 \\
\hline \multirow[t]{2}{*}{ gi|116644211| } & F:AAAAGATGCAACGCTGGAAC & 45.00 \\
\hline & R:ACTGAAACGCGCACATGTAA & 45.00 \\
\hline \multirow[t]{2}{*}{ gi|4387244| } & F:CGCAACTCCTTCTGCTGATG & 55.00 \\
\hline & R:GCAACTGAGTCCTTCGATGT & 50.00 \\
\hline \multirow[t]{2}{*}{ gi $|4386975|$} & F:TCTCCATCTCACCGTCGATG & 55.00 \\
\hline & R:AGCACGGACAGGGGAATTTA & 50.00 \\
\hline \multirow[t]{2}{*}{ gi|4386907| } & F:TTGTGGACTATCGGACCCTG & 55.00 \\
\hline & R:ACCATGGTTCCTGCAGATGA & 50.00 \\
\hline \multirow[t]{2}{*}{ gi $|4386813|$} & F:TGGGGTTTTGTTGTGAGGAA & 45.00 \\
\hline & R:ATATCCGGTGGCCTCGAAAT & 50.00 \\
\hline \multirow[t]{2}{*}{ gi $|4386589|$} & F:GGATTTCTCGCCGGTTAACC & 55.00 \\
\hline & R:TGGAGGATCTGTCAGCTTCG & 55.00 \\
\hline \multirow[t]{2}{*}{ gi $|4386543|$} & F:ACTCCTGAGATGTCGTGCAA & 50.00 \\
\hline & R:TGCCCCACAAAACTCAAACA & 45.00 \\
\hline \multicolumn{3}{|c|}{ Genomic SSR primers } \\
\hline \multirow[t]{2}{*}{ G3 } & F: ACAAACTCAAGATAAGTAAGAGC & 55.3 \\
\hline & R: GTGAATTGTGTTTTAACATGG & 52.0 \\
\hline \multirow[t]{2}{*}{ G5 } & F: CTCTCTCAATGTTTGTCTTTC & 54.0 \\
\hline & R: GCAAGGTAGGTAGCTAGGGA & 59.4 \\
\hline \multirow[t]{2}{*}{ G7 } & F: AGCATGGGAAGAAGACACGT & 57.3 \\
\hline & R: TTGAGCAAAACATCGCAATC & 53.2 \\
\hline \multirow[t]{2}{*}{ G12 } & F: AATTTCGGACCCGCCGAG & 58.2 \\
\hline & R: TTCAACGCCATCGATGC & 52.8 \\
\hline \multirow[t]{2}{*}{ G17 } & F: TTCCTCACTATTTTGAATTGCG & 54.7 \\
\hline & R: TGTACTTCTCTGCAGATTCCA & 55.9 \\
\hline G21 & F: TTGTCGCTTCAGTTTTGGC & 54.5 \\
\hline & R: TTCACCTTGCCACTGTGAAG & 57.3 \\
\hline G22 & F: GCGCACCCAAAGTTGAAG & 56.0 \\
\hline & R: CCTCATAGGGACGCACATAC & 59.4 \\
\hline
\end{tabular}


morphological evaluation. This paves a way toward the development of resistant variety for buckeye rot through breeding. These lines can be further used for quantitative trait loci (QTL) analysis/ gene tagging for buckeye rot.

\section{REFERENCES}

AVRDC. (2004). Tomato diseases. 04-612

Lu, M., Han, Z. and Yao, L. (2013). In vitro and in vivo antimicrobial efficacy of essential oils and individual compounds against Phytophthora parasitica var. nicotianae. J. Appl. Microbiol., 115 (1) : 187-198

Bijaya, A.K., Tewari, R.N. and Verma, T.S. (2002). Screening of tomato varieties/breeding lines against buckeye rot Phytophthora nicotianae var. parasitica Dastur. Indian. J. Hill., Fmg. 15(1):39-43

Bowers, J. H. and Locke, J. C. (2004). Effect of formulated plant extracts and oils on population density of Phytophthora nicotianae in soil and control of Phytophthora blight in the greenhouse. Plant. Dis., 88 (1):11-16

Dodan, D. S., Shyam, K. P. and Bhardwaj, S.S. (1995). Relative response of tomato cultivar lines against Buckeye rot under field conditions. Pl. Dis. Res., 10(2):135-136

Doyle, J. J. and Doyle, J. J. (1987). A rapid DNA isolation procedure from small quantities of fresh leaf tissues. Phytochem. Bul., $19: 11-15$

FAOSTAT. (2015). Global tomato production in 2013; Crops/World/2013. UN Food and Agriculture Organization, Statistics Division. 2015. Retrieved 3 June 2016.

Flores, V. D. I., Gonzalez, G. M. and Ramirez, O. R. (2013). Proposal of a culture medium for the study of Phytophthora nicotianae Breda de Haan. Revista de Cienciay Tecnologia, (19) : 24-27
Gupta, S. K., Upmanyu, S. and Sharma, R. C. (2005). Biology, epidemiology and management of buckeye rot of tomato. In: challenging problems in horticultural and forest pathology. Sharma, R. C. and Sharma, J. N. (eds.). Indus Publishing Co., New Delhi, India Pp. 183199

Jain, S. S., Sharma, S. L. and Juneja, S. L. (1961). Studies on buckeye rot of tomato-new toHimachal Pradesh. Proceedings of Indian Science Congress Association, 50 : 351-352

Kaur, R., Shilpa, Vaidya, E. and Kumar, K. (2015) Development, characterization and transferability of peach genic SSRs to some Rosaceaespecies. Advances in Research, $3: 165-180$

Mehta, S. (2004). Studies on resistance to some fungal diseases and heterosis in tomato (Lycopersicon esculentum Mill.). Ph.D. Thesis. Dr Y. S. Parmar University of Horticulture and Forestry, Nauni, Solan, HP, India.

Olanya, O. M. and Larkin, R. P. (2006). Efficacy of essential oils and biopesticides on Phytophthora infestans suppression in laboratory and growth chamber studies. Biocontrol. Sci. Technol., 16 (9/10) : 901-917

Oliva-Risco, E. (1983). Methods of assessing resistance to Phytophthora infestans in tomato. Centro Agricola., 10 (2) : 35-46

Ribeiro, O. K. (1978). A source book of the genus Phytophthora. Cramer, Vaduz, Liechtenstein. $417 \mathrm{p}$

Sherbakoff, C. D. (1917). Buckeye rot of tomato fruit. Phytopathology, $7: 119-129$

Tiwari, R. K., Mistry, N. C, Singh, B. and Gandhi. C. P. (2014). (eds.). Indian Horticulture Database. Gurgaon: National Horticulture Board Pp. 177-185

Wani, A. H. (2011). An overview of the fungal rot of tomato. Mycopathology, 9(1):33-38 